\title{
From Brussels a Minimum Income as Rossi and Spinelli Dreamed in Their Manifesto
}

\section{Giuseppe Bronzini}

Despite its inefficiencies and often failures, the EU aims not only to combat poverty, but, in a more ambitious dimension, to eradicate the risk of "social exclusion", that is notoriously based on broader and more demanding parameters of various kinds, capable of intercepting every element of mortification of the dignity of the person according to a more complex approach, transcending the disposable income.This element already points out that the EU is still able to reach very advanced levels of planning (often innovative), but with no results matching what had been conceived. The studies on policies contrasting the risk of exclusion, set up since the end of the 1990s on the basis of the socalled "open method of coordination" (OMC), are clearly very advanced at the global level not only for their approach, that brings back into focus the "indecent", underpaid, precarious and discontinuous work (of the so-called working poor), but for their thoughtful and properly supranational character, as they methodically compare the various national approaches and try to select the best practices in an attempt to generalize them (through a sort of European moral suasion), while taking into account national specificities where the competence remained to the individual states. What emerges from this comparison, extended to the social actors, can be read in the annual Joint Report on social inclusion, which is at least a documentary path for understanding in broad terms what was to be done and what was actually done. In the debate on the "constitutionalization" of the EU (which led to the Treaty of Lisbon) it was decided to strengthen the fight against social exclusion, in a double direction: on the one hand, the strengthening of the $\mathrm{OMC}$, through specific provisions of a general competence by the coordinating Union (Articles 4 and 5 TFEU) and, on the other, the establishment of a specific scheme for combating social exclusion (Article153 TFEU), albeit requiring unanimity and without regulatory powers.

On this basis, in the Recommendations annually addressed to Italy by the EC and the Council, the evident shortcomings of the social protection system and the abnormal number of people living below an income sufficient to guarantee a free and dignified existence and not covered by a minimum guaranteed income (MGI), as required by Art. 34 of the Charter of Rights, have always been highlighted. There is to mention the important attempts to arrive at a sort of soft codification of the principles of flexicurity, i.e. the formula with which the EU wants to ensure an existential security for all (December 2007) and the launch of a new general strategy called Europe 20-20, which introduces the new target to reduce by $20 \%$ in ten years the number of those at risk of social exclusion; furthermore, in the TEU (Article 3 ), the fight against social exclusion is one of the objectives of its policies. This is a complex, nontrivial plan, if we also remember Art. 34 of the Charter of Rights, which exerted considerable pressure on the countries lacking effective tools to fight poverty (those in Southern Europe) so that they introduce more suitable protection schemes and a certain mutual contamination of social protection models (at least until 2008), also fueled by the functioning of the common market, 
whose rules (connected by the Court of Justice to the concept of European citizenship) were leading to an opening up of national welfare systems to the access of EU community's migrants. It cannot therefore be said that the Union has been lacking in terms of elaboration, which remains to this day the spearhead of the contemporary reflection on poverty and on the best ways to combat it. Nor can it be said that no instruments have been sought to put ideas into action in any way: what has prevented success on this front has been the explosion of the international economic crisis, which has manifested itself in the old continent as a crisis of the common currency - the euro for which the Union had not set up any efficient institutional system in the face of speculation and the risk of default in the weaker states.

Germany has imposed the adoption of new institutions such as the European Stability Mechanism (ESM), together with strict rules for keeping in check the most exposed states (above all the Fiscal Compact). European policies as a whole have been vigorously redirected towards deficitreduction targets through an austerity philosophy, that ends up aiming at reducing social spending (anyway this has been the choice for all the countries assisted by the ESM or close to default). The EC has never explicitly claimed that MGI measures (in the short term the only tool capable of eradicating poverty) should be reduced and no lightening of the "homework" burden was allowed for such particular social purposes; Germany alsoexcluded any socialization of national debts. Some countries like Portugal or Ireland have not reduced their MGI schemes, but overall the cuts in social spending in all the countries in difficulties constituted the dominant recipe, creating further poverty and social hardships, and annihilating the idea, until 2005 rather widespread, that the Union could guarantee a prosperous future for all its member countries. The solidarity promised in the Treaties seemed even symbolically trampled upon in an Athens deprived of food, medicines and even money, until its surrender to the Brussels institutions.
Thustheveryidea of a European policy (i.e.shared and implemented collectively) to combat poverty through effective instruments, to be subjected to the control and verification of the Brussels institutions, has been sacrificed. The countries who were in a position to, have continued their flexicurity policies; the countries of the North are in agreement with the 20-20 Strategy scheme, the unemployed are at a minimum, and the weakest are protected by MGI systems, in some countries quite generous. Even the pressure on the less virtuous ones seems to have been turned off; the reproaches to Italy, that, the only one among the $28 \mathrm{~s}$, does not have an MGI system minimally coherent with supranational indications $(60 \%$ of the median income in dependent work) and that only in 2017 has introduced a meager subsidy for extreme poverty, conditioned to harassments and humiliation of all kinds for the lucky few (with a very low uptake), are by now very mild.

Italy has doubled the number of its absolute poor since 2008, which reached the shameful number of 5 millions; but social hardships have worsened in all the most "indebted" countries, creating a menacing fracture within the Union and the belief that Europe is not so much a resource but rather the problem. A counter-plan would be needed to regain the trust of Europeans through common but also direct and therefore visible measures, through a shared budget (possibly of the Eurozone) and own resources from supranational taxes capable of supporting realistic projects, quite important on a symbolic level for making people talk once again about a European solidarity. The most influential European social-policy scholars have for some time highlighted as virtuous examples those of a single system against unemployment and of the (at least partial) funding of a European-wide MGI system (a euro-dividend); should a minimum income for the excluded arrive from Brussels (as Rossi and Spinelli dreamed in their Manifesto of 1941), perhaps we could go up the slope again. 